Review Article

\title{
Decellularized Extracellular Matrix as an In Vitro Model to Study the Comprehensive Roles of the ECM in Stem Cell Differentiation
}

\author{
Takashi Hoshiba, ${ }^{1,2}$ Guoping Chen, ${ }^{2}$ Chiho Endo, ${ }^{3}$ Hiroka Maruyama, ${ }^{3}$ \\ Miyuki Wakui, ${ }^{3}$ Eri Nemoto, ${ }^{3}$ Naoki Kawazoe, ${ }^{2}$ and Masaru Tanaka ${ }^{1,4}$ \\ ${ }^{1}$ Frontier Center for Organic Materials, Yamagata University, 4-3-16 Jonan, Yonezawa, Yamagata 992-8510, Japan \\ ${ }^{2}$ Tissue Regeneration Materials Unit, International Center for Materials Nanoarchitectonics, \\ National Institute for Materials Science, 1-1 Namiki, Tsukuba, Ibaraki 305-0044, Japan \\ ${ }^{3}$ Graduate School of Science and Engineering, Yamagata University, 4-3-16 Jonan, Yonezawa, Yamagata 992-8510, Japan \\ ${ }^{4}$ Institute for Materials Chemistry and Engineering, Kyushu University, 744 Motooka, Nishi-ku, Fukuoka, Fukuoka 819-0395, Japan \\ Correspondence should be addressed to Takashi Hoshiba; thoshiba@yz.yamagata-u.ac.jp
}

Received 28 May 2015; Accepted 30 July 2015

Academic Editor: Pedro M. Baptista

Copyright ( 2016 Takashi Hoshiba et al. This is an open access article distributed under the Creative Commons Attribution License, which permits unrestricted use, distribution, and reproduction in any medium, provided the original work is properly cited.

\begin{abstract}
Stem cells are a promising cell source for regenerative medicine. Stem cell differentiation must be regulated for applications in regenerative medicine. Stem cells are surrounded by extracellular matrix (ECM) in vivo. The ECM is composed of many types of proteins and glycosaminoglycans that assemble into a complex structure. The assembly of ECM molecules influences stem cell differentiation through orchestrated intracellular signaling activated by many ECM molecules. Therefore, it is important to understand the comprehensive role of the ECM in stem cell differentiation as well as the functions of the individual ECM molecules. Decellularized ECM is a useful in vitro model for studying the comprehensive roles of ECM because it retains a native-like structure and composition. Decellularized ECM can be obtained from in vivo tissue ECM or ECM fabricated by cells cultured in vitro. It is important to select the correct decellularized ECM because each type has different properties. In this review, tissue-derived and cell-derived decellularized ECMs are compared as in vitro ECM models to examine the comprehensive roles of the ECM in stem cell differentiation. We also summarize recent studies using decellularized ECM to determine the comprehensive roles of the ECM in stem cell differentiation.
\end{abstract}

\section{Introduction}

Stem cells are a promising source of cells for tissue engineering and regenerative medicine. Regenerative medicine applications that utilize stem cells require the regulation of stem cell differentiation $[1,2]$. Stem cell differentiation is regulated by transcription factors that are expressed in specific tissues and organs [3-5]. During stem cell differentiation, the expression of transcription factors is regulated by signals from the extracellular microenvironment, including soluble factors and the extracellular matrix (ECM). Previous research determined that the ECM influences stem cell differentiation and the maintenance of stemness [6-9]. Therefore, it is important to clarify the role of the ECM in stem cell differentiation.

The ECM is a complex structure composed of collagens, proteoglycans, glycoproteins, and glycosaminoglycans. Researchers have studied the effects of individual ECM components on stem cell differentiation by coating single ECM proteins and observing the phenotypes of genetically mutated animals and cells. However, the ECM is composed of many types of proteins and glycosaminoglycans. Cellular functions, such as cell proliferation and differentiation, are precisely tuned by the combination of these molecules $[10,11]$. Therefore, it is necessary to elucidate the comprehensive roles of the assembled ECM in stem cell differentiation as well 
as the roles of single ECM molecules. The in vitro ECM model is useful for these studies. However, it is difficult to construct in vitro ECM models using chemical and physical methods because of the complex composition of the ECM. Decellularized ECM is an alternative in vitro model that can elucidate the comprehensive roles of the ECM. In this review, we summarize the researches that have been conducted to understand the comprehensive roles of the ECM in stem cell differentiation using decellularized ECM as an in vitro ECM model.

\section{General Roles of the ECM in the Regulation of Cellular Functions}

The ECM is composed of many types of collagens, proteoglycans, glycoproteins, and glycosaminoglycans. These molecules are assembled to form a complex structure [10]. The protein components of the ECM vary for different tissues and organs [12]. The composition of the ECM is determined by developmental and pathological conditions [13-15]. The ECM acts as a substrate to facilitate cell adhesion for the formation of tissues and organs. The ECM is also a physical barrier between different tissues [16]. In addition to these physical roles (i.e., a substrate for cell adhesion and a physical barrier), the ECM influences many cellular functions through three modes: (a) mechanical stimulation from substrates with different stiffness, (b) regulation of soluble factor availability and activity, and (c) intracellular signaling activated by cell adhesion molecules (Figure 1).

The stiffness of tissues and organs varies according to their type. Stiffness is partially dependent on the ECM and can influence cellular functions [17-20]. Lo et al. reported that cells could recognize the stiffness of substrates. When cells were cultured on a gel substrate that contained both hard and soft regions, the cells migrated from the soft gel to the hard gel [17]. Mesenchymal stem cells (MSCs) can also recognize the stiffness of a substrate and differentiate into different lineages according to substrate stiffness [18].

ECM proteins can bind several soluble factors, such as bone morphogenetic proteins (BMPs) and Wnt protein, to regulate their activity. Wang et al. reported that BMP signaling was regulated by ECM molecules in Drosophila. Type IV collagen can bind the BMP signaling molecule Decapentaplegic (Dpp) to form a gradient pattern for correct Drosophila development [21]. Wnt protein can bind to ECM proteins such as proteoglycans [22]. The local concentration of Wnt protein increases by binding to the ECM. The accessibility to receptors is increased because of the increased availability of Wnt protein compared to soluble Wnt protein [23]. The ECM can downregulate the activity of soluble factors. Biglycan can bind to chordin, an inhibitor of BMP, to suppress BMP signaling [24].

Additionally, ECM proteins themselves can activate intracellular signaling through the interaction with cell adhesion molecules such as integrins [25]. Integrin activated intracellular signaling regulates various cellular functions such as cell survival, proliferation, morphogenesis, migration, and differentiation $[25,26]$. Integrins are heterodimers

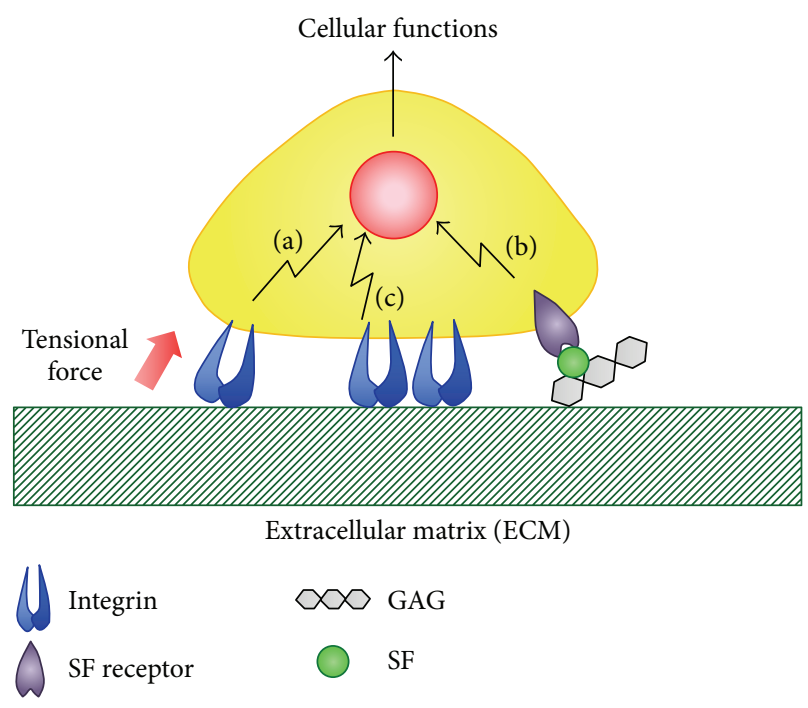

FIGURE 1: Three regulatory modes of cellular functions. (a) The mechanical stimulation from substrates of different stiffness. (b) Signal activation from soluble factors bound to ECM. (c) Signal activation from adhesion molecules such as integrins. SF indicates soluble factor and GAG indicates glycosaminoglycan.

composed of $\alpha$ and $\beta$ chains. The combination of integrin heterodimers determines their ligand specificity [26]. Different combinations of integrin heterodimers activate different intracellular signaling pathways. For example, integrin $\alpha 5 \beta 1$ bound to fibronectin activates extracellular signal-regulated kinase (ERK), whereas integrin $\alpha 3 \beta 1$ bound to laminin511/521 activates Akt rather than ERK [27]. Integrin signaling can cross talk with intracellular signaling activated by growth factors and can modulate their signaling [28]. Several interactions between cells and ECM and the signals activated by these interactions regulate cellular functions. Therefore, it is important to obtain a comprehensive understanding of how the ECM and individual ECM molecules influence stem cell differentiation.

\section{Decellularized ECM as an In Vitro ECM Model}

The composition of the ECM is complex and tissue-specific. It is difficult to obtain an in vitro ECM model that recreates the in vivo ECM composition by simple mixing of single ECM molecules. To solve this problem, decellularized ECM is used as an in vitro ECM model. Decellularized ECM is derived from the tissue and ECM proteins that are deposited by in vitro cultured cells [29-31]. Appropriate decellularization methods are required to obtain decellularized ECM that is similar (in composition and structure) to the original ECM. Decellularization is mainly performed with chemical, physical, and biological treatments and their combinations. Decellularized ECM is often cross-linked for stabilization. The effects of these treatments on the composition of the original ECM have been previously reviewed [29, 32]. The correct treatment should be selected for the preparation of 
TABLE 1: Partial list of tissue/organ-derived decellularized ECMs for stem cell culture.

\begin{tabular}{|c|c|c|c|}
\hline Target stem cell & Source of decellularized ECM & Application & Reference \\
\hline \multirow{4}{*}{$\begin{array}{l}\text { Bone marrow-derived } \\
\text { mesenchymal stem } \\
\text { cells }\end{array}$} & Full thickness ear cartilage & Ear cartilage reconstruction & {$[45]$} \\
\hline & Bladder & Bladder reconstruction & {$[46]$} \\
\hline & Skin (dermal tissue) & Wound healing & {$[47]$} \\
\hline & Brain & Neural differentiation & {$[43]$} \\
\hline $\begin{array}{l}\text { Adipose-derived } \\
\text { mesenchymal stem } \\
\text { cells }\end{array}$ & Adipose tissue & Adipose tissue engineering & {$[48]$} \\
\hline \multirow{2}{*}{$\begin{array}{l}\text { Neural stem cells } \\
\text { (NSCs) }\end{array}$} & Brain sliced section & NSC expansion with undifferentiated state & {$[40]$} \\
\hline & Brain, spinal cord, urinary bladder & Neural differentiation & [41] \\
\hline PC12 cell line & Brain, spinal cord, optic nerve & Neural differentiation & {$[42]$} \\
\hline $\begin{array}{l}\text { Adipose precursor } \\
\text { cells }\end{array}$ & Placenta & $\begin{array}{l}\text { Adipose precursor cell culture for adipose tissue } \\
\text { engineering }\end{array}$ & {$[49]$} \\
\hline Adipose stem cells & Tendon & Tenogenic differentiation & {$[50]$} \\
\hline $\begin{array}{l}\text { Endothelial } \\
\text { progenitor cells }\end{array}$ & Umbilical cord artery & Vascular reconstruction & {$[51]$} \\
\hline Liver stem-like cells & Liver & $\begin{array}{l}\text { Hepatic differentiation, other epithelial-like and } \\
\text { endothelial-like cells }\end{array}$ & {$[44]$} \\
\hline Hair follicle stem cells & Skin (dermal tissue) & Hair bud-like structure formation and hair regeneration & {$[52]$} \\
\hline \multirow{2}{*}{$\begin{array}{l}\text { Induced pluripotent } \\
\text { stem (iPS) cells }\end{array}$} & Lung & Differentiation into lung progenitor cells & {$[53]$} \\
\hline & Heart & Heart reconstruction & {$[54]$} \\
\hline \multirow{2}{*}{$\begin{array}{l}\text { Embryonic stem }(\mathrm{ES}) \\
\text { cells }\end{array}$} & Lung & Lung reconstruction & {$[55]$} \\
\hline & Kidney & Kidney reconstruction & {$[56]$} \\
\hline
\end{tabular}

decellularized ECM. The decellularized ECM source should also be considered for the preparation of decellularized ECM as an in vitro ECM model. We compared tissue-derived and cell-derived decellularized ECM.

3.1. Tissue-Derived Decellularized ECM. Tissues and organs are attractive sources of decellularized ECM because the composition of their decellularized ECM is identical to the composition of native ECM after correct decellularization treatments. Tissue-derived decellularized ECM is expected to exhibit native mechanical properties (e.g., stiffness) and microstructure. Tissue-derived decellularized ECM can be used in several forms, such as whole tissue/organ shapes [33, 34], patch-type shapes [35], coating material for two-dimensional (2D) cell culture substrates [36, 37], and injectable gel $[38,39]$. Tissue-derived decellularized ECM is applied as an in vitro ECM model to regulate stem cell differentiation and to study the comprehensive roles of ECM in stem cell differentiation (Table 1).

Sliced brain sections can be decellularized, and this decellularized ECM can be used as the substrate for the threedimensional (3D) culture of neural stem cells (NSCs) [40]. In decellularized brain ECM, NSCs can attach, proliferate, and retain their stemness [40]. Other researchers reported that decellularized brain ECM facilitated the differentiation of stem cells. Crapo et al. determined that the differentiation of NSCs and PC12 cells into neural cells was facilitated by exposure to decellularized brain ECM [41, 42]. Baiguera et al. reported that MSCs differentiated into neural cells on electrospun gelatin scaffolds that contained decellularized brain ECM [43]. Although the mechanism needs to be clarified, decellularized brain ECM is an attractive scaffold for nerve tissue regeneration.

Liver stem-like cells have been seeded on decellularized liver ECM to guide their differentiation into hepatocytes [44]. In decellularized liver ECM, liver stem-like cells lost the expressing embryonic marker genes encoding $\alpha$-fetoprotein, nestin, nanog, and Oct3/4. The cells expressed hepatic genes encoding albumin and cytochrome P450s indicating their differentiation into hepatocytes. Moreover, liver stem-like cells can also form a subpopulation that expresses the genes encoding cytokeratin 19 and another subpopulation that expresses the genes encoding vimentin and CD31. This result suggests that liver stem-like cells can differentiate into epithelial-like and endothelial-like cells. Therefore, decellularized liver ECM can be used as an in vitro model of liver ECM for liver development.

Murine embryonic stem (ES) cells were seeded into the decellularized ECM derived from whole kidney [56]. In whole kidney-derived decellularized ECM, the ES cells lost their pluripotency and differentiated into a mesoendodermal lineage [56]. Murine ES cells were seeded into the decellularized ECM derived from whole lung [55]. In this decellularized ECM, the cells started to express thyroid transcription factor-1 (an immature lung epithelial cell marker) and prosurfactant protein $C$ (a type II pneumocyte marker). These reports indicate that decellularized ECM can provide cues that direct stem cell differentiation toward specific lineages. 
TABLE 2: Partial list of cell-derived decellularized ECM for stem cell culture.

\begin{tabular}{|c|c|c|c|}
\hline Target stem cell & Source of decellularized ECM & Application & References \\
\hline \multirow{3}{*}{$\begin{array}{l}\text { Embryonic stem } \\
(\mathrm{ES}) \text { cells }\end{array}$} & Fibroblasts & $\begin{array}{l}\text { Establishment of ES cells and maintenance of their } \\
\text { stemness }\end{array}$ & {$[57]$} \\
\hline & Differentiating embryoid body & ES cell proliferation and differentiation & {$[58,59]$} \\
\hline & HEK293 & Pancreatic lineage differentiation. & {$[60]$} \\
\hline \multirow{5}{*}{$\begin{array}{l}\text { Mesenchymal stem } \\
\text { cells (MSCs) }\end{array}$} & Undifferentiated mesenchymal stem cells & $\begin{array}{l}\text { Expansion culture with the maintenance of their } \\
\text { stemness }\end{array}$ & {$[61]$} \\
\hline & Osteoblasts & Osteogenic induction culture & {$[62,63]$} \\
\hline & MSCs under osteogenesis & $\begin{array}{l}\text { Osteogenic induction culture and intracellular signal } \\
\text { analysis }\end{array}$ & {$[64]$} \\
\hline & MSCs under adipogenesis & $\begin{array}{l}\text { Adipogenic induction culture and intracellular signal } \\
\text { analysis }\end{array}$ & {$[65]$} \\
\hline & Chondrocytes & Chondrogenesis & {$[66]$} \\
\hline \multirow{3}{*}{$\begin{array}{l}\text { Hematopoietic } \\
\text { stem cells (HSCs) }\end{array}$} & MSCs & $\begin{array}{l}\text { Expansion culture with the maintenance of their } \\
\text { stemness }\end{array}$ & {$[67]$} \\
\hline & MSCs under osteogenesis & In vitro model of HSC niche & {$[68]$} \\
\hline & MS-5 stromal cell line & Ex vivo expansion culture of HSCs & [69] \\
\hline
\end{tabular}

Although tissue-derived decellularized ECM has several advantages, several features of in vitro ECM models make them inferior for addressing the comprehensive roles of ECM in stem cell differentiation. One of the largest problems is the tissue source. It requires significant quantities of tissuederived decellularized ECM to analyze ECM in vitro. It is difficult to obtain sufficient tissue-derived ECM from both animal and human sources.

In addition to the problem of tissue source, the isolation of small regions from tissue-derived decellularized ECM is difficult. Stem cells are maintained in small regions called niches in adult tissues in vivo. For example, NSCs are maintained in a basement membrane-like ECM called "fractones" that are adjacent to blood vessels in the subependymal layer of the lateral ventricle in the brain $[70,71]$. Stem cell differentiation progresses in small regions in adult tissues $[72,73]$. The composition of the ECM varies during the stem cell differentiation process, and the effects of the ECM on stem cell differentiation may change at each maturational stage $[72,73]$. Therefore, the effects of the ECM on stem cell differentiation should be elucidated using an in vitro ECM model at each maturational stage. It is difficult to identify different maturational regions from tissue-derived decellularized ECM. It is difficult to analyze the comprehensive roles of ECM in stem cell differentiation at each maturational stage in vitro in tissue-derived decellularized ECM.

3.2. Cell-Derived Decellularized ECM. Cell-derived decellularized ECM is also used as an in vitro ECM model to regulate stem cell differentiation and to study the comprehensive roles of the ECM in stem cell differentiation (Table 2). Cells cultured in vitro can deposit ECM proteins beneath themselves [74, 75]. After the deposition of ECM proteins, the cells are specifically removed from the culture to obtain cell-derived decellularized ECM. Cell-derived decellularized ECM is an attractive in vitro ECM model. Abundant cellderived decellularized ECM can be obtained for the in vitro analysis of the comprehensive roles of ECM in stem cell differentiation. It can be obtained in various forms, such as $3 \mathrm{D}$ structural scaffolds $[63,66]$ and $2 \mathrm{D}$ cell culture substrates $[64,65]$. Cell-derived decellularized ECM can be obtained for use as an in vitro ECM model that is difficult to identify and isolate from tissue. Cell-derived decellularized ECM can model the stem cell niche and the ECM at each maturational stage.

The bone marrow stromal cell line MS-5 was cultured for the preparation of cell-derived decellularized ECM. The cellderived decellularized ECM was used as the culture substrate for the ex vivo expansion of hematopoietic stem cells (HSCs) [69]. The MS-5 cells were cultured under different culture conditions (i.e., modulation of $\mathrm{O}_{2}$ tension and osteogenic induction). HSCs proliferated with expression of their specific surface markers on decellularized ECM obtained from cells cultured under low $\mathrm{O}_{2}$ tension. Proteomic analysis was performed to analyze the differences among four MS5 cell-derived decellularized ECMs. The proteomic analysis revealed differential production of proteins such as aldehyde dehydrogenase and gelsolin. Cell-derived decellularized ECM can be obtained from cells cultured under specific conditions. Cell-derived decellularized ECM may reveal the conditions that form an ECM in vivo.

Decellularized ECM, derived from other cell types, was obtained for HSCs as an in vitro model for hematopoietic stem cell niche analysis [68]. Chan et al. prepared collagen particles encapsulating MSCs. Encapsulated MSCs were cultured under osteogenic conditions and then decellularized to obtain decellularized ECM. In this decellularized ECM, MSCs and HSCs were cocultured, and the suppression of HSC proliferation was observed. This result suggested that HSCs were maintained in a quiescent state. Intracellular signaling was examined to identify the mechanism that maintained HSC quiescence. The addition of a BMP2 neutralizing antibody increased the number of HSCs in the decellularized ECM, suggesting that BMP2 signaling is important for 
TABLE 3: Summary of the differences between tissue-derived and cell-derived decellularized ECM.

\begin{tabular}{lll}
\hline & Tissue-derived decellularized ECM & Cell-derived decellularized ECM \\
\hline Advantages & $\begin{array}{l}\text { Similar to native ECM composition, } \\
\text { mechanical properties, and } \\
\text { microstructure. }\end{array}$ & $\begin{array}{l}\text { (i) Easy to obtain ECM model of small } \\
\text { tissue regions. } \\
\text { (ii) Possible for large-scale in vitro } \\
\text { analysis. }\end{array}$ \\
\hline Disadvantages & $\begin{array}{l}\text { (i) Problems with ECM source. } \\
\text { (ii) Difficult for large-scale in vitro } \\
\text { analysis. } \\
\text { (iii) Difficult to isolate small region from decellularized ECM } \\
\text { tissue. }\end{array}$ & $\begin{array}{l}\text { whose composition, mechanical } \\
\text { properties, and microstructure are } \\
\text { identical to native ECM. }\end{array}$ \\
\hline
\end{tabular}

the maintenance of HSC quiescence. Cell-derived decellularized ECM may be a useful in vitro ECM model to elucidate the interactions in the HSC niche.

Although cell-derived decellularized ECM has several advantages over tissue-derived ECM in the in vitro analysis of the comprehensive roles of ECM in stem cell differentiation, it is difficult to obtain cell-derived decellularized ECM with the composition, mechanical properties, and microstructure which are identical to in vivo ECM. The composition of cellderived ECM is dependent on the cell type and the cell culture conditions. The composition varies between decellularized ECM derived from primary versus passaged chondrocytes, leading to different cellular functions [76]. Alveolar type II epithelial cells form a basement membrane- (BM-) like structure with cocultured fibroblasts or Matrigel. However, alveolar type II epithelial cells are unable to form a BMlike structure without these coculture conditions [77, 78]. The initial cell culture substrate used for the preparation of decellularized ECM can influence the function of cells cultured on it [79]. The cell culture conditions used for decellularized ECM preparation should be carefully determined. A summary of the differences between tissue-derived decellularized ECM and cell-derived decellularized ECM is reported in Table 3.

\section{Cellular Functions on Tissue Development-Mimicking Matrices}

Stem cells differentiate into somatic cells step-by-step both in vivo and in vitro $[3,4]$. The ECM is dynamically remodeled at each maturational stage according to this stepwise stem cell differentiation process [80, 81]. In vitro ECM models that mimic the composition of the native ECM at each maturational stage are necessary to gain a comprehensive understanding of the roles of the ECM in stem cell differentiation. Stem cell differentiation occurs in limited regions in adult tissues, and it is difficult to isolate such limited regions for the preparation of tissue-derived decellularized ECM. Cell-derived decellularized ECM is an excellent model for ECM that is difficult to identify and isolate from tissues. Therefore, cell-derived decellularized ECM is useful for the preparation of in vitro models of ECM surrounding stem cells and differentiating cells at each maturational stage. The ECM surrounding mesenchymal stem cells (MSCs) and differentiating MSCs has been thoroughly studied using cellderived decellularized ECM. We summarized the research involving cellular functions on cell-derived decellularized ECM mimicking in vivo ECM surrounding MSCs and differentiating cells. We also summarized the trials analyzing intracellular signaling on decellularized ECM.

4.1. Stemness Maintenance of MSCs on Undifferentiated MSCDerived Decellularized ECM. The ECM is an important component of stem cell niches that maintains a stem cell's undifferentiated state and its stemness $[6,7]$. MSCs gradually lose their stemness through in vitro passage culture. The loss of stemness prevents the large-scale application of MSCs in regenerative medicine [61]. Chen and his colleagues used undifferentiated MSC-derived decellularized ECM to solve this problem $[61,82]$. MSCs maintained their ability to differentiate into other cell lineages after in vitro passage culture on undifferentiated MSC-derived decellularized ECM. This ability was lost in passage culture on conventional plastic cell culture substrates. MSCs subcultured on conventional plastic substrates decreased their ability to differentiate after five passages and lost it completely after six to seven passages. Cells subcultured on undifferentiated MSC-derived decellularized ECM maintained this ability after seven passages [61]. Spontaneous and induced differentiation of MSCs was suppressed on undifferentiated MSC-derived decellularized ECM $[64,82]$. MSC proliferation is promoted on undifferentiated MSC-derived decellularized ECM [64].

Undifferentiated MSC-derived decellularized ECM has been used as an in vitro model of the ECM in the MSC niche to analyze intracellular signaling. BMPs play important roles in the differentiation of MSCs. BMP signaling activation is suppressed on decellularized ECM to prevent the spontaneous and induced differentiation of MSCs [64, 82]. Wnt signaling is activated on decellularized ECM to suppress osteogenesis [64, 83].

Intracellular levels of reactive oxygen species were also suppressed to maintain MSC characteristics on decellularized ECM [84]. Cellular senescence in vitro is also involved in stemness maintenance [85]. Telomerase activity was retained at higher levels on decellularized ECM than on conventional plastic substrate to inhibit stem cell replicative senescence during in vitro culture [84]. However, the mechanisms underlying such phenomena are still unclear. The molecular 


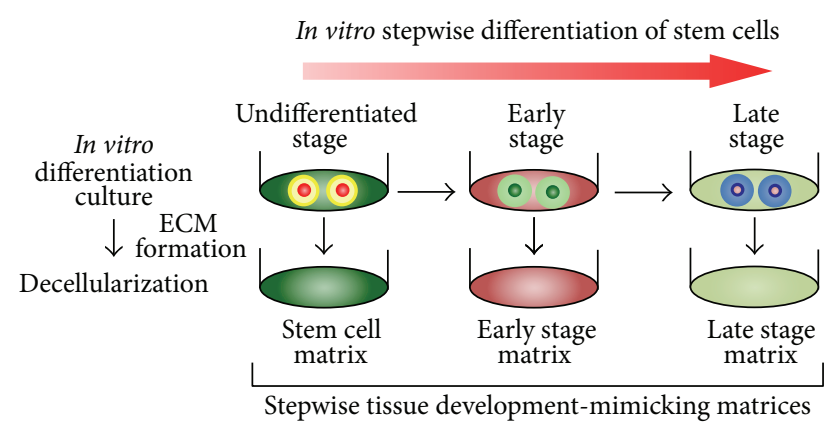

FIGURE 2: The concept and preparation procedure of stepwise tissue development-mimicking matrices.

mechanisms by which decellularized ECM promotes telomerase activity and suppresses cell senescence must be identified.

4.2. Differentiation of MSCs on Tissue Development-Mimicking Matrices. MSC differentiation occurs step-by-step in vitro [86]. Therefore, it is possible that cell-deposited ECM can be obtained as decellularized ECM at each maturational stage. We have reported "stepwise osteogenesis-mimicking matrices" and "stepwise adipogenesis-mimicking matrices" as in vitro ECM models mimicking in vivo ECM at each stage of MSC osteogenesis and adipogenesis [64, 65, 83, 87]. These stepwise osteogenesis-mimicking matrices and stepwise adipogenesis-mimicking matrices were obtained through decellularization treatment of in vitro osteogenic and adipogenic MSC cultures. All decellularized ECMs were referred to as "stepwise tissue development-mimicking matrices” (Figure 2).

According to the progression of MSC differentiation, the composition of the ECM surrounding differentiating cells changes dynamically [88, 89]. This behavior suggests that ECM remodeling influences MSC differentiation. MSCs exhibit different osteogenic and adipogenic patterns on tissue development-mimicking matrices at different maturational stages. The osteogenesis of MSCs was only promoted on early osteogenic stage decellularized ECM. It was not promoted on decellularized ECM from late osteogenic or adipogenic stages $[64,87]$. Conversely, the adipogenesis of MSCs was only promoted on early adipogenic stage decellularized ECM, and it was not promoted on decellularized ECM from late adipogenic or osteogenic stages $[65,87]$. These results indicated that the differentiation of MSCs requires tissue- and stage-specific ECM [87].

The molecular mechanisms of MSC differentiation on tissue development-mimicking matrices were examined [64, $65,87]$. MSC differentiation is controlled by transcription factors such as runt-related transcription factor 2 (RUNX2, also known as CBFA1), peroxisome proliferator-activated receptor $\gamma(\operatorname{PPAR} \gamma)$, and transcriptional activators such as transcriptional coactivator with PDZ-binding motif (TAZ) $[5,90,91]$. The expression levels of these molecules were measured on tissue development-mimicking matrices during the osteogenesis and adipogenesis of MSCs. The expression of RUNX2, which promotes osteogenesis, increased on decellularized ECM from early and late osteogenic stages but not on decellularized ECM from undifferentiated or adipogenic stages $[64,87]$. The expression of PPARG, which promotes adipogenesis and inhibits osteogenesis, also increased on late osteogenic stage decellularized ECM $[64,87]$. PPARG expression was suppressed on decellularized ECM from undifferentiated and early osteogenic stages. These results suggested that early osteogenic stage ECM promotes the osteogenesis of MSCs and suppresses unexpected MSC differentiation (Figure 3(a)).

Similar to the osteogenesis of MSCs on tissue development-mimicking matrices, the expression patterns of transcription factors relating to adipogenesis differed for the different tissue development-mimicking matrices. Few differences in PPARG expression were observed during the adipogenesis of MSCs on tissue development-mimicking matrices. In contrast to PPARG expression, RUNX2 expression levels increased on decellularized ECM from osteogenic stages but not that from adipogenic or undifferentiated stages $[65,87]$. The expression level of $T A Z$, which promotes osteogenesis and inhibits adipogenesis, decreased only on decellularized ECM from the early adipogenic stage $[65,87]$. Therefore, ECM at the early adipogenic stage demonstrated inhibitory effects on osteogenesis rather than stimulatory effects on adipogenesis (Figure 3(b)).

The regulatory mechanism of $P P A R G$ expression was examined on stepwise osteogenesis-mimicking matrices. PPARG expression was regulated by $\beta$-catenin signaling during the osteogenesis and adipogenesis of MSCs [92]. Intracellular $\beta$ catenin levels increased on decellularized ECM from undifferentiated and early osteogenic stages to suppress PPARG expression [64]. Intracellular $\beta$-catenin levels are regulated by canonical Wnt signaling [93]. However, the expression of Wnt signal-related genes such as CTNNB1, LRP5, and WNT3A did not change on decellularized ECM. Intracellular $\beta$-catenin levels decreased on decellularized ECM with treatment by chondroitinase $\mathrm{ABC}$, which can remove chondroitin sulfate (CS) chains. Wnt protein can bind to CS chains to present to its receptors on cell surfaces [83]. The removal of CS chains decreased the availability of Wnt protein for the cells, and intracellular $\beta$-catenin levels decreased on the decellularized ECM treated with chondroitinase ABC.

Tissue development-mimicking matrices can be used as in vitro ECM models to study the comprehensive roles of ECM in stem cell differentiation and to clarify the intracellular signaling activated by interaction with the ECM.

4.3. Disadvantages to Cell-Derived Decellularized ECM. Cellderived decellularized ECM is a powerful in vitro model for analyzing the comprehensive roles of the ECM in stem cell differentiation. However, there are some disadvantages to using this substrate that require further investigation. The ECM is composed of many proteins and glycosaminoglycans produced by various cell types [12]. For example, the ECM in the NSC niches called "fractones" is adjacent to blood vessels, and endothelial cells and NSCs can supply ECM molecules for fractones [70, 71]. Therefore, the cell source for the preparation of cell-derived decellularized ECM should 


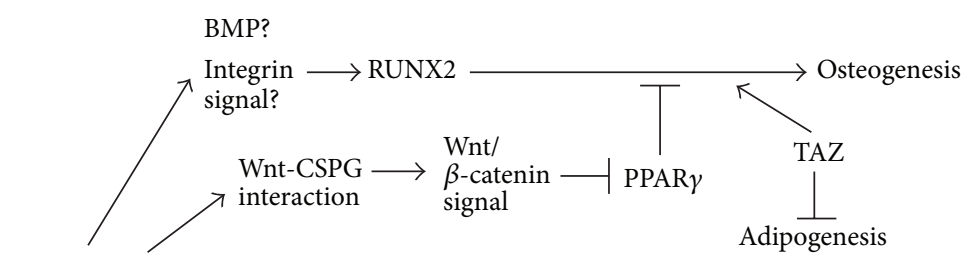

Osteogenic early stage matrix

(a) Role of ECM in osteogenesis

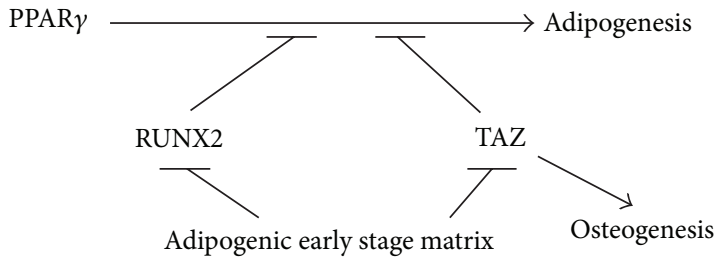

(b) Role of ECM in adipogenesis

FIGURE 3: MSC differentiation mechanism on tissue development-mimicking matrices. (a) Role of tissue- and stage-specific ECM in the osteogenesis of MSCs. (b) Role of tissue- and stage-specific ECM in the adipogenesis of MSCs.

be considered carefully. The composition of the cell-derived decellularized ECM should be compared with the composition of the target ECM in vivo.

It is also important to understand how the effects of single ECM molecules on cellular functions are integrated to regulate stem cell differentiation. To answer this puzzling question, it is important to compare the effects between decellularized ECM and single ECM molecules on cellular functions.

\section{Conclusions}

Stem cells can exhibit different functions, such as proliferation and differentiation, on different types of decellularized ECM. Tissue-derived or cell-derived decellularized ECM can be used as an in vitro ECM model. The correct type of decellularized ECM should be selected because both decellularized ECM types have advantages and disadvantages. The results must be interpreted carefully from the viewpoint of similarity of decellularized ECM with the ECM in vivo. In spite of this consideration, decellularized ECM is one of the best ECM models mimicking native ECM composition and structure. Therefore, decellularized ECM is a powerful model for studying the comprehensive roles of ECM in stem cell differentiation.

\section{Conflict of Interests}

The authors declare that there is no conflict of interests regarding the publication of this paper.

\section{Acknowledgments}

This research is supported by a Grant-in-Aid for Young Scientists (A) (2672016), funded by the Ministry of Education, Culture, Sports, Science, and Technology (MEXT) of Japan. This research is also supported by the Center of Innovation Program from the Japan Science and Technology Agency (JST).

\section{References}

[1] P. Bianco and P. G. Robey, "Stem cells in tissue engineering," Nature, vol. 414, no. 6859, pp. 118-121, 2001.
[2] D. E. Discher, D. J. Mooney, and P. W. Zandstra, "Growth factors, matrices, and forces combine and control stem cells," Science, vol. 324, no. 5935, pp. 1673-1677, 2009.

[3] K. A. D’Amour, A. G. Bang, S. Eliazer et al., "Production of pancreatic hormone-expressing endocrine cells from human embryonic stem cells," Nature Biotechnology, vol. 24, no. 11, pp. 1392-1401, 2006.

[4] T. Kinoshita and A. Miyajima, "Cytokine regulation of liver development," Biochimica et Biophysica Acta-Molecular Cell Research, vol. 1592, no. 3, pp. 303-312, 2002.

[5] P. Ducy, R. Zhang, V. Geoffroy, A. L. Ridall, and G. Karsenty, "Osf2/Cbfal: a transcriptional activator of osteoblast differentiation," Cell, vol. 89, no. 5, pp. 747-754, 1997.

[6] Y. Bi, D. Ehirchiou, T. M. Kilts et al., "Identification of tendon stem/progenitor cells and the role of the extracellular matrix in their niche," Nature Medicine, vol. 13, no. 10, pp. 1219-1227, 2007.

[7] F. M. Watt and B. L. M. Hogan, "Out of eden: stem cells and their niches," Science, vol. 287, no. 5457, pp. 1427-1430, 2000.

[8] Y. Bi, C. H. Stuelten, T. Kilts et al., "Extracellular matrix proteoglycans control the fate of bone marrow stromal cells," Journal of Biological Chemistry, vol. 280, no. 34, pp. 3048130489, 2005.

[9] T. Rozario and D. W. DeSimone, "The extracellular matrix in development and morphogenesis: a dynamic view," Developmental Biology, vol. 341, no. 1, pp. 126-140, 2010.

[10] R. O. Hynes, "The extracellular matrix: not just pretty fibrils," Science, vol. 326, no. 5957, pp. 1216-1219, 2009.

[11] A. Takawale, S. S. Sakamuri, and Z. Kassiri, "Extracellular matrix communication and turnover in cardiac physiology and pathology," Comprehensive Physiology, vol. 5, no. 2, pp. 687-719, 2015.

[12] R.-I. Manabe, K. Tsutsui, T. Yamada et al., "Transcriptomebased systematic identification of extracellular matrix proteins," Proceedings of the National Academy of Sciences of the United States of America, vol. 105, no. 35, pp. 12849-12854, 2008.

[13] C. Bonnans, J. Chou, and Z. Werb, "Remodelling the extracellular matrix in development and disease," Nature Reviews Molecular Cell Biology, vol. 15, no. 12, pp. 786-801, 2014.

[14] S. Tom, J. Parkinson, M. Z. Ilic, J. Cook, J. A. Feller, and C. J. Handley, "Changes in the composition of the extracellular matrix in patellar tendinopathy," Matrix Biology, vol. 28, no. 4, pp. 230-236, 2009.

[15] Z. Werb and J. R. Chin, "Extracellular matrix remodeling during morphogenesis," Annals of the New York Academy of Sciences, vol. 857, pp. 110-118, 1998. 
[16] E. Adachi, I. Hopkinson, and T. Hayashi, "Basement-membrane stromal relationships: interactions between collagen fibrils and the lamina densa," International Review of Cytology, vol. 173, pp. 73-156, 1997.

[17] C.-M. Lo, H.-B. Wang, M. Dembo, and Y.-L. Wang, "Cell movement is guided by the rigidity of the substrate," Biophysical Journal, vol. 79, no. 1, pp. 144-152, 2000.

[18] A. J. Engler, S. Sen, H. L. Sweeney, and D. E. Discher, "Matrix elasticity directs stem cell lineage specification," Cell, vol. 126, no. 4, pp. 677-689, 2006.

[19] M. J. Paszek, N. Zahir, K. R. Johnson et al., "Tensional homeostasis and the malignant phenotype," Cancer Cell, vol. 8, no. 3, pp. 241-254, 2005.

[20] A. J. Engler, M. A. Griffin, S. Sen, C. G. Bönnemann, H. L. Sweeney, and D. E. Discher, "Myotubes differentiate optimally on substrates with tissue-like stiffness: pathological implications for soft or stiff microenvironments," The Journal of Cell Biology, vol. 166, no. 6, pp. 877-887, 2004.

[21] X. Wang, R. E. Harris, L. J. Bayston, and H. L. Ashe, “Type IV collagens regulate BMP signalling in Drosophila," Nature, vol. 455, no. 7209, pp. 72-77, 2008.

[22] H. Wang, W. Sun, J. Ma, Y. Pan, L. Wang, and W.-B. Zhang, "Biglycan mediates suture expansion osteogenesis via potentiation of Wnt/ $\beta$-catenin signaling," Journal of Biomechanics, vol. 48, no. 3, pp. 432-440, 2015.

[23] X. Lin, "Functions of heparan sulfate proteoglycans in cell signaling during development," Development, vol. 131, no. 24, pp. 6009-6021, 2004.

[24] M. Moreno, R. Muñoz, F. Aroca, M. Labarca, E. Brandan, and J. Larraín, "Biglycan is a new extracellular component of the Chordin-BMP4 signaling pathway," The EMBO Journal, vol. 24, no. 7, pp. 1397-1405, 2005.

[25] F. G. Giancotti and E. Ruoslahti, "Integrin signaling," Science, vol. 285, no. 5430, pp. 1028-1032, 1999.

[26] R. O. Hynes, "Integrins: bidirectional, allosteric signaling machines," Cell, vol. 110, no. 6, pp. 673-687, 2002.

[27] J. Gu, A. Fujibayashi, K. M. Yamada, and K. Sekiguchi, "Laminin-10/11 and fibronectin differentially prevent apoptosis induced by serum removal via phosphatidylinositol 3kinase/Akt- and MEK1/ERK-dependent pathways," The Journal of Biological Chemistry, vol. 277, no. 22, pp. 19922-19928, 2002.

[28] P. M. Comoglio, C. Boccaccio, and L. Trusolino, "Interactions between growth factor receptors and adhesion molecules: breaking the rules," Current Opinion in Cell Biology, vol. 15, no. 5, pp. 565-571, 2003.

[29] T. W. Gilbert, T. L. Sellaro, and S. F. Badylak, "Decellularization of tissues and organs," Biomaterials, vol. 27, no. 19, pp. 36753683, 2006.

[30] S. F. Badylak, "The extracellular matrix as a biologic scaffold material," Biomaterials, vol. 28, no. 25, pp. 3587-3593, 2007.

[31] T. Hoshiba, H. Lu, N. Kawazoe, and G. Chen, "Decellularized matrices for tissue engineering," Expert Opinion on Biological Therapy, vol. 10, no. 12, pp. 1717-1728, 2010.

[32] B. Joddar, T. Hoshiba, G. Chen, and Y. Ito, "Stem cell culture using cell-derived substrates," Biomaterials Science, vol. 2, no. 11, pp. 1595-1603, 2014.

[33] H. C. Ott, T. S. Matthiesen, S.-K. Goh et al., "Perfusion-decellularized matrix: using nature's platform to engineer a bioartificial heart," Nature Medicine, vol. 14, no. 2, pp. 213-221, 2008.

[34] B. E. Uygun, A. Soto-Gutierrez, H. Yagi et al., "Organ reengineering through development of a transplantable recellularized liver graft using decellularized liver matrix," Nature Medicine, vol. 16, no. 7, pp. 814-820, 2010.

[35] M. Kajitani, Y. Wadia, M. T. Hinds, J. Teach, K. R. Swartz, and K. W. Gregory, "Successful repair of esophageal injury using an elastin based biomaterial patch," ASAIO Journal, vol. 47, no. 4, pp. 342-345, 2001.

[36] M. Rojkind, Z. Gatmaitan, S. Mackensen, M. A. Giambrone, P. Ponce, and L. M. Reid, "Connective tissue biomatrix: its isolation and utilization for long-term cultures of normal rat hepatocytes," Journal of Cell Biology, vol. 87, no. 1, pp. 255-263, 1980.

[37] T. L. Sellaro, A. K. Ravindra, D. B. Stolz, and S. F. Badylak, "Maintenance of hepatic sinusoidal endothelial cell phenotype in vitro using organ-specific extracellular matrix scaffolds," Tissue Engineering, vol. 13, no. 9, pp. 2301-2310, 2007.

[38] J. M. Singelyn, J. A. DeQuach, S. B. Seif-Naraghi, R. B. Littlefield, P. J. Schup-Magoffin, and K. L. Christman, "Naturally derived myocardial matrix as an injectable scaffold for cardiac tissue engineering," Biomaterials, vol. 30, no. 29, pp. 5409-5416, 2009.

[39] J. M. Singelyn and K. L. Christman, "Injectable materials for the treatment of myocardial infarction and heart failure: the promise of decellularized matrices," Journal of Cardiovascular Translational Research, vol. 3, no. 5, pp. 478-486, 2010.

[40] J. De Waele, K. Reekmans, J. Daans, H. Goossens, Z. Berneman, and P. Ponsaerts, "3D culture of murine neural stem cells on decellularized mouse brain sections," Biomaterials, vol. 41, pp. 122-131, 2015.

[41] P. M. Crapo, S. Tottey, P. F. Slivka, and S. F. Badylak, "Effects of biologic scaffolds on human stem cells and implications for CNS tissue engineering," Tissue Engineering Part A, vol. 20, no. 1-2, pp. 313-323, 2014.

[42] P. M. Crapo, C. J. Medberry, J. E. Reing et al., "Biologic scaffolds composed of central nervous system extracellular matrix," Biomaterials, vol. 33, no. 13, pp. 3539-3547, 2012.

[43] S. Baiguera, C. D. Gaudio, E. Lucatelli et al., "Electrospun gelatin scaffolds incorporating rat decellularized brain extracellular matrix for neural tissue engineering," Biomaterials, vol. 35, no. 4, pp. 1205-1214, 2014.

[44] V. Navarro-Tableros, M. B. Herrera Sanchez, F. Figliolini, R. Romagnoli, C. Tetta, and G. Camussi, "Recellularization of rat liver scaffolds by human liver stem cells," Tissue Engineering, Part A, vol. 21, no. 11-12, pp. 1929-1939, 2015.

[45] L. Utomo, M. M. Pleumeekers, L. Nimeskern et al., "Preparation and characterization of a decellularized cartilage scaffold for ear cartilage reconstruction," Biomedical Materials, vol. 10, no. 1, Article ID 015010, 2015.

[46] D. L. Coutu, W. Mahfouz, O. Loutochin, J. Galipeau, and J. Corcos, "Tissue engineering of rat bladder using marrowderived mesenchymal stem cells and bladder acellular matrix," PLoS ONE, vol. 9, no. 12, Article ID el11966, 2014.

[47] Q. Wang, Y. Jin, X. Deng et al., "Second-harmonic generation microscopy for assessment of mesenchymal stem cell-seeded acellular dermal matrix in wound-healing," Biomaterials, vol. 53, pp. 659-668, 2015.

[48] L. Wang, J. A. Johnson, Q. Zhang, and E. K. Beahm, "Combining decellularized human adipose tissue extracellular matrix and adipose-derived stem cells for adipose tissue engineering," Acta Biomaterialia, vol. 9, no. 11, pp. 8921-8931, 2013.

[49] L. Flynn, J. L. Semple, and K. A. Woodhouse, "Decellularized placental matrices for adipose tissue engineering," Journal of Biomedical Materials Research, vol. 79, no. 2, pp. 359-369, 2006. 
[50] G. Yang, B. B. Rothrauff, H. Lin, R. Gottardi, P. G. Alexander, and R. S. Tuan, "Enhancement of tenogenic differentiation of human adipose stem cells by tendon-derived extracellular matrix," Biomaterials, vol. 34, no. 37, pp. 9295-9306, 2013.

[51] A. Constantinescu, E. Andrei, F. Iordache, E. Constantinescu, and H. Maniu, "Recellularization potential assessment of Wharton's Jelly-derived endothelial progenitor cells using a human fetal vascular tissue model," In Vitro Cellular \& Developmental Biology-Animal, vol. 50, no. 10, pp. 937-944, 2014.

[52] G. J. Leirós, A. G. Kusinsky, H. Drago et al., "Dermal papilla cells improve the wound healing process and generate hair budlike structures in grafted skin substitutes using hair follicle stem cells," Stem Cells Translational Medicine, vol. 3, no. 10, pp. 12091219, 2014.

[53] S. E. Gilpin, X. Ren, T. Okamoto et al., "Enhanced lung epithelial specification of human induced pluripotent stem cells on decellularized lung matrix," Annals of Thoracic Surgery, vol. 98, no. 5, pp. 1721-1729, 2014.

[54] T.-Y. Lu, B. Lin, J. Kim et al., "Repopulation of decellularized mouse heart with human induced pluripotent stem cell-derived cardiovascular progenitor cells," Nature Communications, vol. 4, article 2307, 2013.

[55] J. Cortiella, J. Niles, A. Cantu et al., "Influence of acellular natural lung matrix on murine embryonic stem cell differentiation and tissue formation," Tissue Engineering Part A, vol. 16, no. 8, pp. 2565-2580, 2010.

[56] B. Bonandrini, M. Figliuzzi, E. Papadimou et al., "Recellularization of well-preserved acellular kidney scaffold using embryonic stem cells," Tissue Engineering Part A, vol. 20, no. 9-10, pp. 1486-1498, 2014.

[57] I. Klimanskaya, Y. Chung, L. Meisner, J. Johnson, M. D. West, and R. Lanza, "Human embryonic stem cells derived without feeder cells," The Lancet, vol. 365, no. 9471, pp. 1636-1641, 2005.

[58] S.-K. Goh, P. Olsen, and I. Banerjee, "Extracellular matrix aggregates from differentiating embryoid bodies as a scaffold to support ESC proliferation and differentiation," PLOS ONE, vol. 8, no. 4, Article ID e61856, 2013.

[59] R. Nair, S. Shukla, and T. C. McDevitt, "Acellular matrices derived from differentiating embryonic stem cells," Journal of Biomedical Materials Research - Part A, vol. 87, no. 4, pp. 10751085, 2008.

[60] Y. Higuchi, N. Shiraki, K. Yamane et al., "Synthesized basement membranes direct the differentiation of mouse embryonic stem cells into pancreatic lineages," Journal of Cell Science, vol. 123, no. 16, pp. 2733-2742, 2010.

[61] Y. Lai, Y. Sun, C. M. Skinner et al., "Reconstitution of marrowderived extracellular matrix ex vivo: a robust culture system for expanding large-scale highly functional human mesenchymal stem cells," Stem Cells and Development, vol. 19, no. 7, pp. 1095$1107,2010$.

[62] N. Datta, H. L. Holtorf, V. I. Sikavitsas, J. A. Jansen, and A. G. Mikos, "Effect of bone extracellular matrix synthesized in vitro on the osteoblastic differentiation of marrow stromal cells," Biomaterials, vol. 26, no. 9, pp. 971-977, 2005.

[63] N. Datta, Q. P. Pham, U. Sharma, V. I. Sikavitsas, J. A. Jansen, and A. G. Mikos, "In vitro generated extracellular matrix and fluid shear stress synergistically enhance 3D osteoblastic differentiation," Proceedings of the National Academy of Sciences of the United States of America, vol. 103, no. 8, pp. 2488-2493, 2006.

[64] T. Hoshiba, N. Kawazoe, T. Tateishi, and G. Chen, "Development of stepwise osteogenesis-mimicking matrices for the regulation of mesenchymal stem cell functions," The Journal of Biological Chemistry, vol. 284, no. 45, pp. 31164-31173, 2009.

[65] T. Hoshiba, N. Kawazoe, T. Tateishi, and G. Chen, "Development of extracellular matrices mimicking stepwise adipogenesis of mesenchymal stem cells," Advanced Materials, vol. 22, no. 28, pp. 3042-3047, 2010.

[66] H. Lu, T. Hoshiba, N. Kawazoe, I. Koda, M. Song, and G. Chen, "Cultured cell-derived extracellular matrix scaffolds for tissue engineering," Biomaterials, vol. 32, no. 36, pp. 9658-9666, 2011.

[67] M. C. Prewitz, F. P. Seib, M. von Bonin et al., "Tightly anchored tissue-mimetic matrices as instructive stem cell microenvironments," Nature Methods, vol. 10, no. 8, pp. 788-794, 2013.

[68] W. Y. Lai, Y. Y. Li, S. K. Mak et al., "Reconstitution of bone-like matrix in osteogenically differentiated mesenchymal stem cellcollagen constructs: a three-dimensional in vitro model to study hematopoietic stem cell niche," Journal of Tissue Engineering, vol. 4, Article ID 2041731413508668, 2013.

[69] A. Tiwari, M. L. Tursky, D. Mushahary et al., "Ex vivo expansion of haematopoietic stem/progenitor cells from human umbilical cord blood on acellular scaffolds prepared from MS-5 stromal cell line," Journal of Tissue Engineering and Regenerative Medicine, vol. 7, no. 11, pp. 871-883, 2013.

[70] A. Kerever, J. Schnack, D. Vellinga et al., "Novel extracellular matrix structures in the neural stem cell niche capture the neurogenic factor fibroblast growth factor 2 from the extracellular milieu," Stem Cells, vol. 25, no. 9, pp. 2146-2157, 2007.

[71] V. Douet, A. Kerever, E. Arikawa-Hirasawa, and F. Mercier, "Fractone-heparan sulphates mediate FGF-2 stimulation of cell proliferation in the adult subventricular zone," Cell Proliferation, vol. 46, no. 2, pp. 137-145, 2013.

[72] K. A. Moore and I. R. Lemischka, "Stem cells and their niches," Science, vol. 311, no. 5769, pp. 1880-1885, 2006.

[73] A. Spradling, D. Drummond-Barbosa, and T. Kai, "Stem cells find their niche," Nature, vol. 414, no. 6859, pp. 98-104, 2001.

[74] T. Hoshiba, C. S. Cho, A. Murakawa, Y. Okahata, and T. Akaike, "The effect of natural extracellular matrix deposited on synthetic polymers on cultured primary hepatocytes," Biomaterials, vol. 27, no. 26, pp. 4519-4528, 2006.

[75] T. Hoshiba, M. Wakejima, C.-S. Cho, G. Shiota, and T. Akaike, "Different regulation of hepatocyte behaviors between natural extracellular matrices and synthetic extracellular matrices by hepatocyte growth factor," Journal of Biomedical Materials Research A, vol. 85, no. 1, pp. 228-235, 2008.

[76] T. Hoshiba, T. Yamada, H. Lu, N. Kawazoe, and G. Chen, "Maintenance of cartilaginous gene expression on extracellular matrix derived from serially passaged chondrocytes during in vitro chondrocyte expansion," Journal of Biomedical Materials Research Part A, vol. 100, no. 3, pp. 694-702, 2012.

[77] A. Furuyama, K. Kimata, and K. Mochitate, "Assembly of basement membrane in vitro by cooperation between alveolar epithelial cells and pulmonary fibroblasts," Cell Structure and Function, vol. 22, no. 6, pp. 603-614, 1997.

[78] A. Furuyama and K. Mochitate, "Assembly of the exogenous extracellular matrix during basement membrane formation by alveolar epithelial cells in vitro," Journal of Cell Science, vol. 113, no. 5, pp. 859-868, 2000.

[79] T. Hoshiba and M. Tanaka, "Optimization of the tissue source, malignancy, and initial substrate of tumor cell-derived matrices to increase cancer cell chemoresistance against 5-fluorouracil," Biochemical and Biophysical Research Communications, vol. 457, no. 3, pp. 353-357, 2015. 
[80] W. P. Daley, S. B. Peters, and M. Larsen, "Extracellular matrix dynamics in development and regenerative medicine," Journal of Cell Science, vol. 121, no. 3, pp. 255-264, 2008.

[81] A. Page-McCaw, A. J. Ewald, and Z. Werb, "Matrix metalloproteinases and the regulation of tissue remodelling," Nature Reviews Molecular Cell Biology, vol. 8, no. 3, pp. 221-233, 2007.

[82] X.-D. Chen, V. Dusevich, J. Q. Feng, S. C. Manolagas, and R. L. Jilka, "Extracellular matrix made by bone marrow cells facilitates expansion of marrow-derived mesenchymal progenitor cells and prevents their differentiation into osteoblasts," Journal of Bone and Mineral Research, vol. 22, no. 12, pp. 1943-1956, 2007.

[83] T. Hoshiba, N. Kawazoe, and G. Chen, "Mechanism of regulation of PPARG expression of mesenchymal stem cells by osteogenesis-mimicking extracellular matrices," Bioscience, Biotechnology and Biochemistry, vol. 75, no. 11, pp. 2099-2104, 2011.

[84] Y. Sun, W. Li, Z. Lu et al., "Rescuing replication and osteogenesis of aged mesenchymal stem cells by exposure to a young extracellular matrix," The FASEB Journal, vol. 25, no. 5, pp. 14741485, 2011.

[85] T. B. L. Kirkwood, "Understanding the odd science of aging," Cell, vol. 120, no. 4, pp. 437-447, 2005.

[86] P. J. Marie, “Transcription factors controlling osteoblastogenesis," Archives of Biochemistry and Biophysics, vol. 473, no. 2, pp. 98-105, 2008.

[87] T. Hoshiba, N. Kawazoe, and G. Chen, "The balance of osteogenic and adipogenic differentiation in human mesenchymal stem cells by matrices that mimic stepwise tissue development," Biomaterials, vol. 33, no. 7, pp. 2025-2031, 2012.

[88] J.-X. Zhu, Y. Sasano, I. Takahashi, I. Mizoguchi, and M. Kagayama, "Temporal and spatial gene expression of major bone extracellular matrix molecules during embryonic mandibular osteogenesis in rats," The Histochemical Journal, vol. 33, no. 1, pp. 25-35, 2001.

[89] I. Nakajima, T. Yamaguchi, K. Ozutsumi, and H. Aso, "Adipose tissue extracellular matrix: newly organized by adipocytes during differentiation," Differentiation, vol. 63, no. 4, pp. 193200, 1998.

[90] S. Mandrup and M. D. Lane, "Regulating adipogenesis," The Journal of Biological Chemistry, vol. 272, no. 9, pp. 5367-5370, 1997.

[91] J.-H. Hong, E. S. Hwang, M. T. McManus et al., "TAZ, a transcriptional modulator of mesenchymal stem cell differentiation," Science, vol. 309, no. 5737, pp. 1074-1078, 2005.

[92] M. Okamura, H. Kudo, K.-I. Wakabayashi et al., "COUP-TFII acts downstream of $\mathrm{Wnt} / \beta$-catenin signal to silence PPAR $\gamma$ gene expression and repress adipogenesis," Proceedings of the National Academy of Sciences of the United States of America, vol. 106, no. 14, pp. 5819-5824, 2009.

[93] T. C. Prestwich and O. A. MacDougald, "Wnt/ $\beta$-catenin signaling in adipogenesis and metabolism," Current Opinion in Cell Biology, vol. 19, no. 6, pp. 612-617, 2007. 

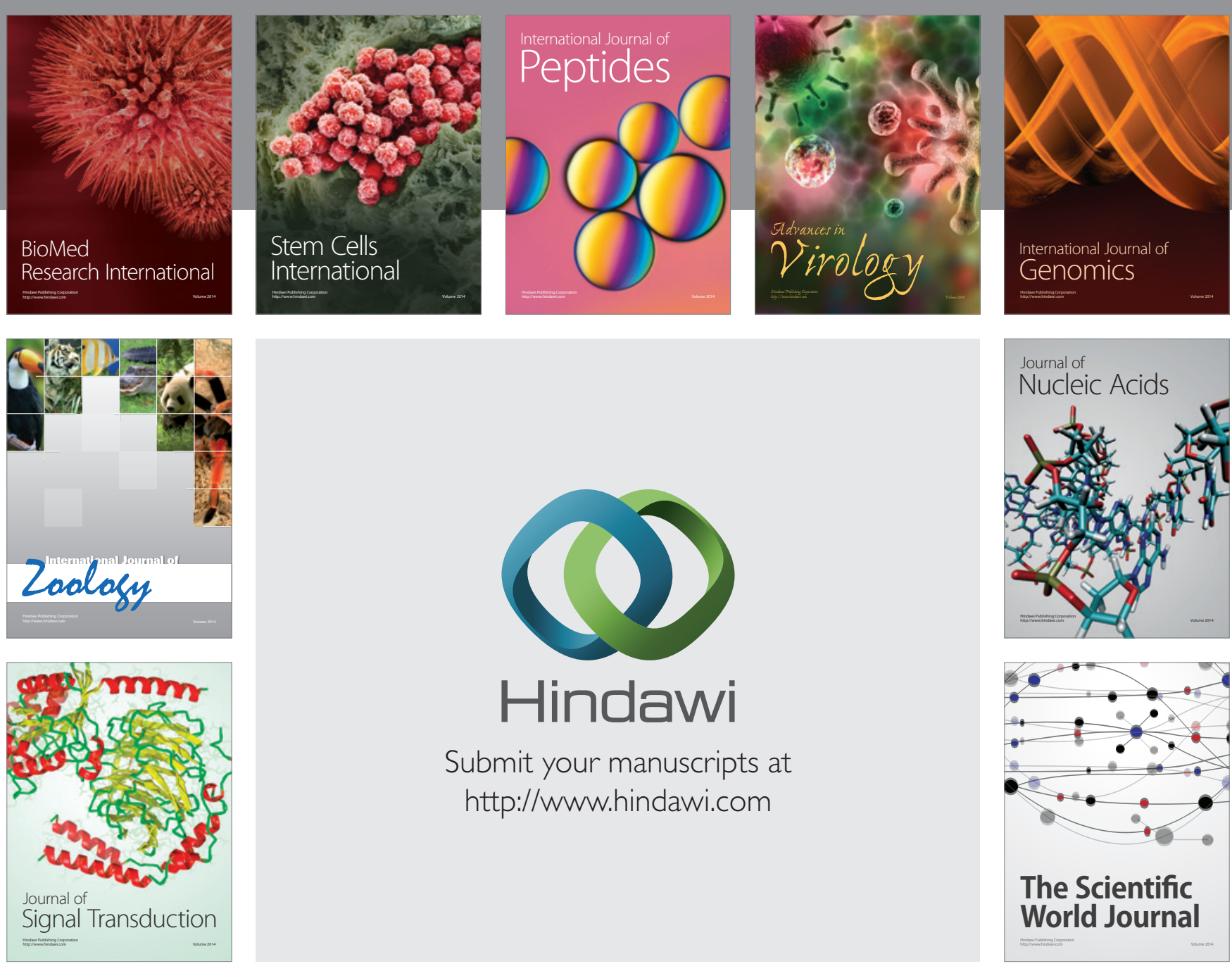

Submit your manuscripts at

http://www.hindawi.com
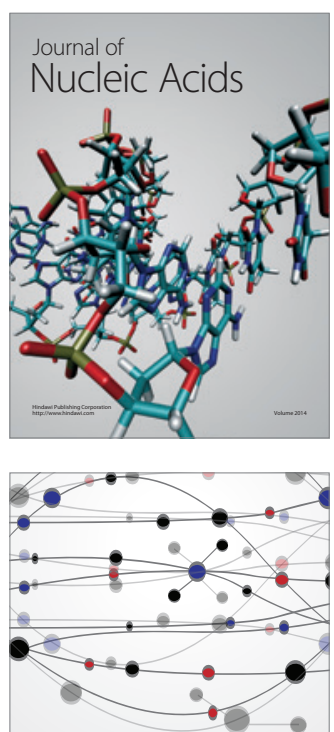

The Scientific World Journal
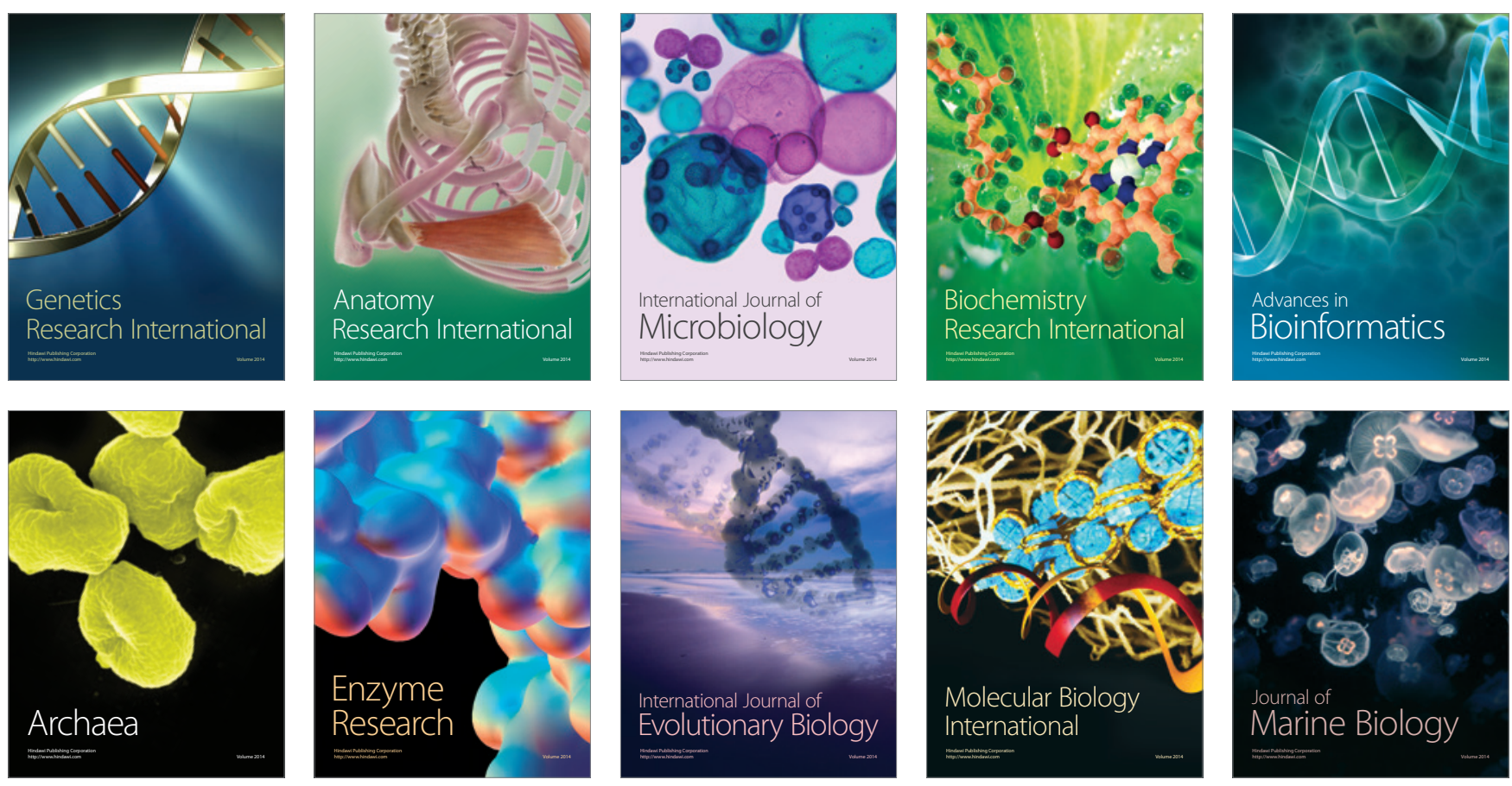